\title{
Brain-Derived Neurotrophic Factor Induces Long-Term Potentiation in Intact Adult Hippocampus: Requirement for ERK Activation Coupled to CREB and Upregulation of Arc Synthesis
}

\author{
Shui-Wang Ying, ${ }^{1 *}$ Marie Futter, ${ }^{2 \star}$ Kobi Rosenblum, ${ }^{2}$ Mark J. Webber, ${ }^{3}$ Stephen P. Hunt, ${ }^{3}$ Timothy V. P. Bliss, ${ }^{2}$ \\ and Clive R. Bramham 1
}

${ }^{1}$ Department of Physiology and Locus on Neuroscience, University of Bergen, N-5009 Bergen, Norway, ${ }^{2}$ Division of Neurophysiology, National Institute for Medical Research, London NW7 1AA, United Kingdom, and ${ }^{3}$ Department of Anatomy and Developmental Biology, University College London, London WC1E 6BT, United Kingdom

Brain-derived neurotrophic factor (BDNF) is implicated in longterm synaptic plasticity in the adult hippocampus, but the cellular mechanisms are little understood. Here we used intrahippocampal microinfusion of BDNF to trigger long-term potentiation (BDNF-LTP) at medial perforant path-granule cell synapses in vivo. BDNF infusion led to rapid phosphorylation of the mitogen-activated protein (MAP) kinases ERK (extracellular signal-regulated protein kinase) and p38 but not JNK (c-Jun $\mathrm{N}$-terminal protein kinase). These effects were restricted to the infused dentate gyrus; no changes were observed in microdissected CA3 and CA1 regions. Local infusion of MEK (MAP kinase kinase) inhibitors (PD98059 and U0126) during BDNF delivery abolished BDNF-LTP and the associated ERK activation. Application of MEK inhibitor during established BDNF-LTP had no effect. Activation of MEK-ERK is therefore required for the induction, but not the maintenance, of BDNF-LTP. BDNFLTP was further coupled to ERK-dependent phosphorylation of the transcription factor cAMP response element-binding protein. Finally, we investigated the expression of two immediate early genes, activity-regulated cytoskeleton-associated protein (Arc) and Zif268, both of which are required for generation of late, mRNA synthesis-dependent LTP. BDNF infusion resulted in selective upregulation of mRNA and protein for Arc. In situ hybridization showed that Arc transcripts are rapidly and extensively delivered to granule cell dendrites. U0126 blocked Arc upregulation in parallel with BDNF-LTP. The results support a model in which BDNF triggers long-lasting synaptic strengthening through MEK-ERK and selective induction of the dendritic mRNA species Arc.

Key words: brain derived neurotrophic factor; BDNF; longterm potentiation; LTP; extracellular signal-regulated protein kinase; ERK; mitogen-activated protein kinase; MAPK; activityregulated cytoskeleton-associated protein; Arc; synaptic plasticity; hippocampus; dentate gyrus
Neurotrophins play diverse roles in regulating neuronal structure, function, and survival during development and into adulthood (Song and Poo, 1999; Bibel and Barde, 2000; Kaplan and Miller, 2000). Recent studies suggest that one of the neurotrophins, brain-derived neurotrophic factor (BDNF), plays a critical role in long-term synaptic plasticity in the adult brain (Schuman, 1999; Schinder and Poo, 2000). The weight of evidence stems from studies of long-term potentiation (LTP) of glutamatergic synapses in the adult hippocampus. LTP, evoked by high-frequency afferent stimulation (HFS-LTP), is typically divided into an early, labile phase dependent on covalent modifications of existing proteins and a late, stable phase requiring new synthesis of mRNA and protein (Bliss and Collingridge, 1993; Nguyen and Kandel, 1996). Experiments involving inhibition of endogenous BDNF and signaling through its TrkB receptor tyrosine kinase suggest that BDNF is required for generating late LTP (Patterson et al., 1996; Figurov et al., 1996; Kang et al., 1997; Korte et al.,

\footnotetext{
Received Sept. 5, 2001; revised Dec. 3, 2001; accepted Dec. 5, 2001.

This work was supported by European Union Biotechnology Program Grant BIO4-CT98-0333. BDNF was provided by Amgen-Regeneron Partners.

*S.W.Y. and M.F. contributed equally to this work.

Correspondence should be addressed to Dr. Clive Bramham, Department of Physiology, University of Bergen, Årstadveien 19, N-5009 Bergen, Norway. E-mail: clive.bramham@pki.uib.no.

Dr. Ying's present address: Department of Anesthesiology A-1050, Weill Medical College of Cornell University, 525 E. 68th Street, New York, NY 10021.

Copyright (C) 2002 Society for Neuroscience $\quad 0270-6474 / 02 / 221532-09 \$ 15.00 / 0$
}

1998; Chen et al., 1999; Minichiello et al., 1999). However, the mechanism of BDNF action is little understood.

Exogenously applied BDNF has a range of rapid, short-lasting effects depending on the developmental stage of the preparation and the method of application (Schinder and Poo, 2000). In cultured immature hippocampal neurons, BDNF evokes a transient facilitation of excitatory synaptic transmission lasting on the order of minutes (Lessmann and Heumann, 1998; Li et al., 1998; Crozier et al., 1999). This contrasts with the situation in the adult hippocampus in which exogenous BDNF can evoke lasting changes in synaptic efficacy. In a series of studies using bath perfusion of BDNF onto hippocampal slices, Schuman and colleagues demonstrated long-lasting enhancement of transmission at Schaffer collateral-CA1 synapses (Kang and Schuman, 1995, 1996; Kang et al., 1997). For reasons that are still unresolved, possibly related to synaptic access of BDNF, these in vitro findings have not been replicated (Kang et al., 1996; Patterson et al., 1996; Frerking et al., 1998). However, using intrahippocampal infusion of BDNF in the intact rat, we observed robust longlasting potentiation at perforant path-granule cell synapses in the dentate gyrus (Messaoudi et al., 1998).

This effect, termed BDNF-induced LTP (or BDNF-LTP), provides a tool for elucidating BDNF mechanisms in synaptic plasticity. If BDNF participates in triggering late LTP, it should somehow regulate new protein synthesis. New proteins could derive from translation of existing mRNA and/or from new 
transcription. Schuman and colleagues have provided evidence that BDNF stimulates protein synthesis in dendrites from existing mRNA (Kang and Schuman, 1996; Aakalu et al., 2001). However, long-term cellular responses to neurotrophins such as differentiation and survival require transcription. Current models of late HFS-LTP suggest a mechanism requiring activation of the extracellular signal-regulated protein kinase (ERK), ERKdependent phosphorylation of the nuclear transcription factor calcium- and cAMP-response element binding protein (CREB), and the subsequent transcription of CRE-driven genes (Impey et al., 1996, 1998; Davis et al., 2000). Two calcium-regulated immediate early genes, activity-regulated cytoskeleton-associated protein (Arc, also known as Arg3.1) and Zif268, were demonstrated recently to be required in late LTP and long-term memory (Guzowski et al., 2000; Jones et al., 2001). These genes are likely to have very distinct functions in late LTP; Arc mRNA is rapidly transported to dendrites and translated, whereas Zif268 regulates the transcription of late response genes.

Here we explored the mechanism of BDNF-LTP in the dentate gyrus in vivo. Using local microinfusion of selective inhibitors of ERK activation and immunoblotting for phosphorylated ERK, we demonstrate a requirement for ERK activation in the induction, but not the expression, of BDNF-LTP. We further show ERK-dependent activation of CREB and robust upregulation of Arc mRNA and protein. Interestingly, Zif268 was not affected. The results support a model in which BDNF triggers long-lasting synaptic strengthening through MEK [MAP (mitogen-activated protein) kinase kinase]-ERK and selective induction of the dendritic mRNA species Arc.

\section{MATERIALS AND METHODS}

Subjects. Data was obtained from 94 male Mol:SD rats (M\&B A/S, Ry, Denmark), weighing 250-320 gm. Animals were housed in a temperature- and light-controlled vivarium $\left(23 \pm 0.5^{\circ} \mathrm{C}\right.$; lights on at 7:00 A.M., lights off at 7:00 P.M.) and supplied with food (12-14 pellets per rat per day) and water for at least 1 week before surgery.

Drugs. Human recombinant met-BDNF (a gift from AmgenRegeneron Partners, Thousand Oaks, CA) was obtained as a concentrated stock solution $(1.0 \mathrm{mg} / \mathrm{ml})$ in PBS $(150 \mathrm{~mm} \mathrm{NaCl}, 10 \mathrm{~mm}$ sodium phosphate buffer, $\mathrm{pH} 7.0$, and $0.004 \%$ Tween 20), aliquoted in small volumes, and stored at $-80^{\circ} \mathrm{C}$ until use. Recombinant cytochrome $c$ from yeast was obtained from Sigma (St. Louis, MO). PD98059 was obtained from Calbiochem-Novabiochem (La Jolla, CA), and U0126 (1,4diamino-2, 3-dicyano-1-4-bis [2-aminophynylthio] butadiene) was generously provided by Dr. James Trzaskos (DuPont Pharmaceuticals, Wilmington, DE). The MEK inhibitors were dissolved in DMSO and diluted in PBS to a final concentration of $30 \mu \mathrm{M}$ inhibitor containing $0.3 \%$ DMSO.

Electrophysiology and intrahippocampal infusion. The procedure for combined recording of medial perforant path-evoked responses and intrahippocampal infusion was identical to that of Messaoudi et al. (1998) with minor modifications. Rats were anesthetized with urethane (1.4-1.8 gm/kg, i.p.), positioned in a stereotaxic frame with the upper incisor bar $2 \mathrm{~mm}$ below the interaural line (skull flat position) and given supplemental doses of urethane as required to maintain a surgical level of anesthesia. Rectal temperature was maintained at $36^{\circ} \mathrm{C}$ with a thermostatically controlled electric heating pad. Stimulating electrodes were bipolar, concentric, stainless steel with a vertical tip separation of $500 \mu \mathrm{m}$ (SNEX 100; Rhodes Medical Instruments, Woodland Hills, CA). A Teflon-coated stainless steel wire (outer diameter of $112 \mu \mathrm{m}$ ) was used for recording. Stereotaxic coordinates for stimulation of the medial perforant path in the dorsomedial aspect of the angular bundle were as follows (in $\mathrm{mm}$ ): 8.0 posterior to bregma, 4.3-4.4 lateral to the midline, and 1.8-2.4 below the dura. Coordinates for recording in the dentate hilus were as follows (in $\mathrm{mm}$ ): $3.8-4.0$ posterior to bregma, 2.2-2.4 lateral, and 3.0-3.1 below the dura.

Intrahippocampal infusions were made using a stainless steel cannula system (Plastics One, Roanoke, VA) consisting of an outer guide tube (24 gauge) and an inner infusion tube (31 gauge). The guide cannula was beveled sharp at the tip to facilitate brain insertion. The recording electrode was glued (cyanoacrylate, Mega-G base; Mega Metal, Oslo, Norway) to the shaft of the outer cannula and cut so that the electrode tip extended $900 \mu \mathrm{m}$ below the cannula tip. After making a small slit in the dura, this guide cannula-electrode assembly was slowly lowered until a positive-going field EPSP (fEPSP) of maximum slope was obtained in the dentate hilus. The final depth of the recording electrode ranged between 300 and $400 \mu \mathrm{m}$ below the level of the maximum negative-going fEPSP sink recorded in the middle-third of the dentate molecular layer. The infusion cannula was then inserted so that the tip protruded $300 \mu \mathrm{m}$ below the end of the guide cannula. The inf usion site was located $\sim 100$ $\mu \mathrm{m}$ above the dentate gyrus (corresponding to deep CA1 stratum lacunosum-moleculare), $300 \mu \mathrm{m}$ above the medial perforant path-granule cell synapses. Responses were allowed to stabilize for at least $1 \mathrm{hr}$ before starting collection of baseline responses.

Biphasic rectangular pulses of $150 \mu$ sec duration were applied every 30 sec throughout the experiment. The stimulation intensity for test pulses was set to elicit population spike amplitude of $30 \%$ of the maximal response. The infusion cannula was connected via PE50 polyethylene tubing to a $5 \mu$ l Hamilton syringe. Solutions were delivered by an infusion pump at a rate of $80 \mathrm{nl} / \mathrm{min}$. BDNF was infused over $25 \mathrm{~min}$ giving a total dose of $2 \mu \mathrm{g}$. This dose corresponds to the lowest dose giving maximal BDNF-LTP (Messaoudi et al., 1998). The MEK inhibitors were applied at a concentration $(30 \mu \mathrm{M})$ that blocks ERK activation in response to HFS-LTP in hippocampal slices.

Tissue microdissection and sample preparation. At the end of electrophysiological recording, rats were decapitated, and the brain was rapidly removed and rinsed with oxygenated ice-cold artificial CSF (in mM: 124.0 $\mathrm{NaCl}, 25.0 \mathrm{NaHOC}_{3}, 10.0$ D-glucose, $3.4 \mathrm{KCl}, 1.2 \mathrm{KH}_{2} \mathrm{PO}_{4}, 1.0 \mathrm{MgSO}_{4}$, and $2.5 \mathrm{CaCL}_{2}, \mathrm{pH}$ 7.4). The dentate gyrus and hippocampal CA1 and CA3 regions were rapidly dissected on ice. Tissues were handhomogenized with 15 strokes in $300 \mu$ l of freshly made SDS sample buffer containing $10 \%$ glycerol, $2.3 \%$ SDS, $0.01 \%$ bromophenol blue, and $0.5 \% \beta$-mercaptoethanol in $62.5 \mathrm{~mm}$ Tris- $\mathrm{HCl}, \mathrm{pH} 6.8$ at room temperature. Homogenates were boiled for $5 \mathrm{~min}$, aliquoted into Eppendorf tubes, and stored at $-80^{\circ} \mathrm{C}$ until use.

SDS-PAGE and Western blotting. Aliquots in SDS sample buffer were subjected to SDS-PAGE and Western blot analysis. Protein levels were determined using the Lowry method, and all gels were loaded with equal amounts of protein. Western blots were performed using $10 \%$ tricine gels $(1 \mathrm{~mm})$ and Novex (Wadsworth, OH) apparatus. SDS-PAGE gels $(10 \%)$ were run for $\sim 1 \mathrm{hr}$ at a constant voltage of $125 \mathrm{~V}$. After the run, proteins were transferred to nitrocellulose at a constant voltage of $50 \mathrm{~V}$. Blots were blocked in $5 \%$ BSA on a gyro-rocker at $4^{\circ} \mathrm{C}$ overnight or for $1 \mathrm{hr}$ at room temperature. Primary antibodies recognized either the active, phosphorylated form (p) or total protein and were anti-dual p-ERK (detects ERK1/2 MAPKs phosphorylated at Thr ${ }^{202}$ and $\mathrm{Tyr}^{204}$; 1:2000; New England Biolabs, Beverly, MA), p-JNK (c-Jun N-terminal protein kinase)/SAPK1 (stress-activated protein kinase), p-p38/SAPK2, p-CREB (detects phosphorylation at Ser ${ }^{133}$; 1:500; New England Biolabs), ERK1/2, JNK/SAPK1, p38/SAPK2, CREB (1:1000; New England Biolabs), Arc (1:500; Santa Cruz Biotechnology, Santa Cruz, CA), and Zif268 (1:1000). The primary antibody was diluted in Tris-buffered saline solution containing $0.1 \%$ Tween 20 (TBST) and 5\% BSA as specified above, and the blots incubated for $2 \mathrm{hr}$ or $4^{\circ} \mathrm{C}$ overnight with constant shaking. After three washes with TBST, blots were incubated with HRP-labeled protein A (1:25000 in TBST; Zymed, San Francisco, CA) or HRP-labeled donkey anti-goat $\operatorname{IgG}$ (1:20000 in TBST; Jackson ImmunoResearch, West Grove, PA). Blots were developed using enhanced chemiluminescence after washing in TBST. Blots were first treated with anti-phospho-specific antibody, stripped with $100 \mathrm{~mm}$ 2-mercaptoethanol, $2 \%$ SDS, and $62.5 \mathrm{~mm}$ Tris- $\mathrm{HCl}, \mathrm{pH} 6.7,50^{\circ} \mathrm{C}$ for $30 \mathrm{~min}$, and reprobed with an antibody recognizing total protein. Autoradiographs was scanned on a laser densitometer and quantitated using ImageQuant software (Amersham Biosciences, Sunnyvale, CA). Western blots were developed to be linear in the range used for densitometry.

In situ hybridization histochemistry. Antisense oligonucleotides (45mers) were synthesized (Oswel DNA Service) complementary to Arc (nucleotides 961-1005) (Lyford et al., 1995) and Zif268 (nucleotides 355-399) (Milbrandt, 1987). Oligonucleotides were $3^{\prime}$ end-labeled with $\left[{ }^{35} \mathrm{~S}\right] \mathrm{dATP}(1200 \mathrm{Ci} / \mathrm{mmol}$; NEN, Boston, MA) in a 30:1 ratio of radiolabeled ATP/oligonucleotide using terminal deoxynucleotidyl transferase (Promega, Madison, WI). Specific activity of the ${ }^{35}$ S-labeled probe was between 100,000 and $300,000 \mathrm{cpm} / \mu \mathrm{l}$ probe. Hybridizations were performed essentially as described by Wisden et al. (1990). Cryostat sections 
a

Figure 1. MEK inhibitors block BDNF-LTP. Time course plots of medial perforant pathevoked fEPSP and population (Pop) spike responses. Test pulses were applied at a rate of 1 every $30 \mathrm{sec}$. BDNF $(2 \mu \mathrm{g} / 2 \mu \mathrm{l})$ was infused $300 \mu \mathrm{m}$ above the medial perforant-granule cell synapses, during the period indicated by the white bar. $n=16$. $a$, Effect of PD98059 on BDNF-LTP. Infusion of $1 \mu \mathrm{l}$ of PD98059 (30 $\mu \mathrm{M})$ was followed immediately by infusion of 2 $\mu \mathrm{g}$ of BDNF in $2 \mu \mathrm{l}$ of PD98059. The period of MEK inhibitor (black bar) and BDNF plus MEK inhibitor (hatched bar) application are indicated. Values are means \pm SEM expressed in percentage of baseline. $n=8$. Inset above shows traces of averaged field responses (5 sweeps) recorded at the time points indicated. $b$, Effect of U0126 (30 $\mu \mathrm{M})$ on BDNF-LTP in a separate groups of animals. $n=8$. BDNF-LTP development is abolished by both MEK inhibitors. The group receiving BDNF alone is the same in $a$ and $b . c$, Cytochrome $c(2 \mu \mathrm{g} / 2 \mu \mathrm{l}$; $n=8$ ) had no significant effect on baseline transmission. $d$, PD98059 (30 $\mu \mathrm{M} ; n=6)$ and U0126 (30 $\mu \mathrm{M} ; n=4)$ applied alone had no effect on baseline synaptic transmission. fEPSP slope data are shown. Insets are averaged traces as done in $c$. Infusion of PBS-DMSO vehicle also had no effect on baseline transmission $(n=4$; data not shown). Calibration: $3 \mathrm{mV}, 4$ msec.

b

C

0
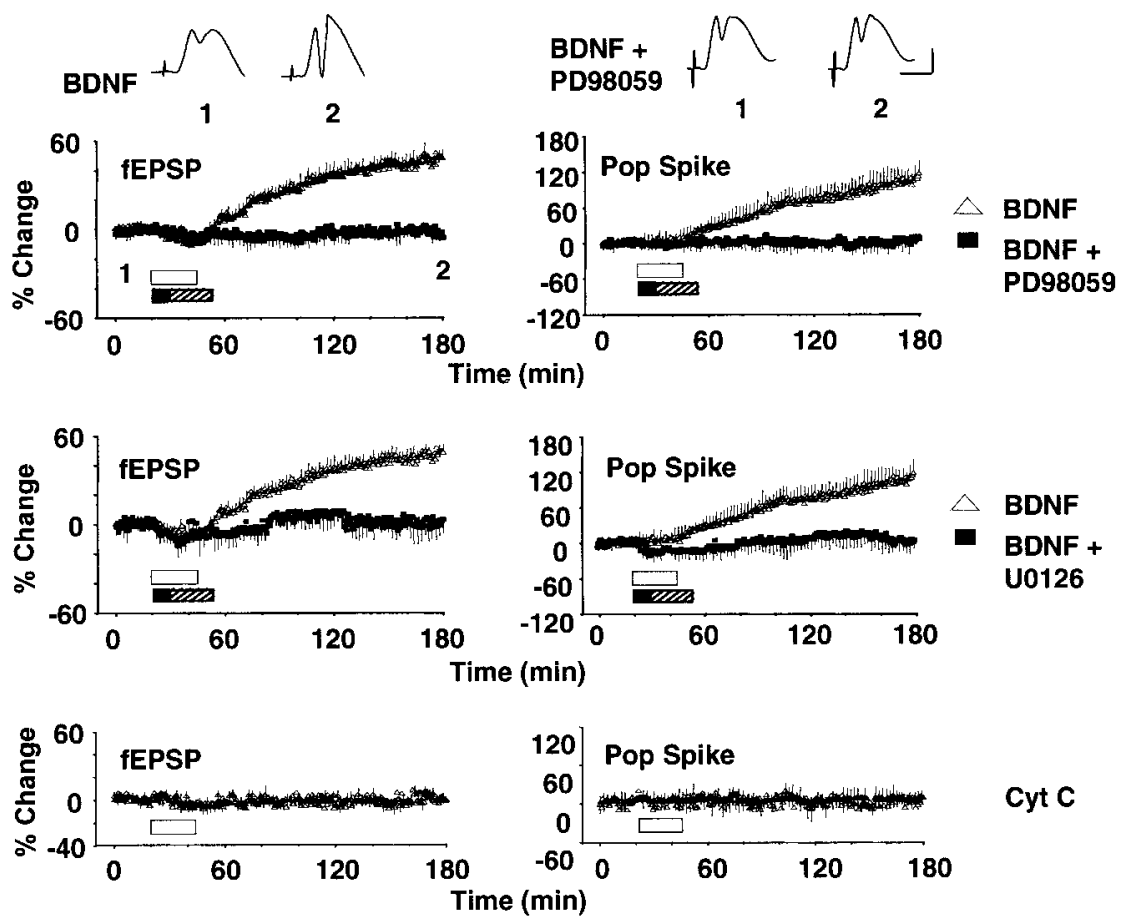

Cyt C
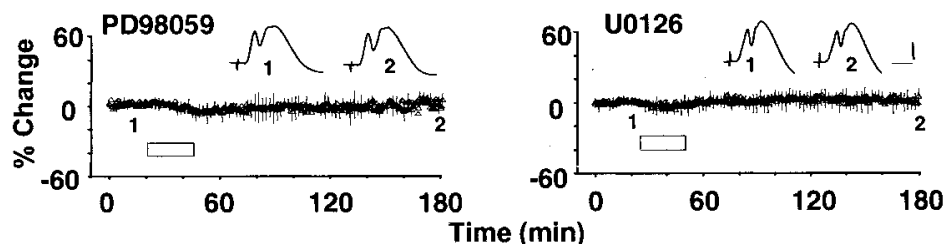

(15 $\mu \mathrm{m})$ were mounted on polylysine-coated slides, dehydrated, and stored in $95 \%$ ethanol. Sections to undergo in situ hybridization were air dried for $1-2 \mathrm{hr} .{ }^{35} \mathrm{~S}$-radiolabeled oligonucleotide probes were hybridized to the sections in a sealed humid chamber at $42^{\circ} \mathrm{C}$ for $14-18 \mathrm{hr}$. The sections then underwent three washes of decreasing stringency (two washes of $1 \times \mathrm{SSC}$ at $55^{\circ} \mathrm{C}$ for $30 \mathrm{~min}$; one wash of $0.1 \times \mathrm{SSC}$ at room temperature for $1 \mathrm{~min})$. Sections were dehydrated, air-dried, and then opposed to Kodak (Eastman Kodak, Rochester, NY) Biomax MR x-ray film for 1-2 weeks. To define nonspecific hybridization, adjacent slidemounted sections were incubated with radiolabeled oligonucleotide in the presence of an excess $(100 \times)$ concentration of unlabeled oligonucleotide probe.

Data processing and statistical analysis. Signals from the dentate hilus were amplified, filtered $(1 \mathrm{~Hz}$ to $3 \mathrm{kHz})$, digitized $(25 \mathrm{kHz}$ for field potentials), and stored to computer disk. Acquisition and analysis of field potentials were accomplished using DataWave Technologies (Longmont, CO) WorkBench software. The maximum slope of the fEPSP and the amplitude of the population spike was measured from its negative-going apex to the tangent line joining the first two positive peaks. Statistical analysis of electrophysiological data are based comparison of the last 10 min of baseline recording with 10 min recording sessions obtained after BDNF treatment as indicated.

For Western blot analysis, optical density values obtained from the treated hippocampus were normalized relative to values in the nontreated hippocampus for each microdissected region. Statistics were performed using a paired $t$ test for dependent samples for the immunoblot data and a one-way repeated-measures ANOVA for the electrophysiology data. Differences were considered significant when $p<0.05$.

\section{RESULTS}

\section{MEK inhibitors block induction of BDNF-LTP in vivo}

TrkB receptors are coupled to three main signaling pathways, including the Ras-ERK protein kinase cascade, phospho- inositide-3 kinase, and phospholipase C. The Ras-ERK pathway is critical for long-term responses requiring gene expression, such as neuronal differentiation and growth (Kaplan and Miller, 2000). ERK is activated by MEK (MAPK, or ERK, kinase), a dual specificity kinase that phosphorylates ERK on $\mathrm{Thr}^{202}$ and $\mathrm{Tyr}^{204}$. We first explored the role of ERK activation in BDNF-LTP pharmacologically, using intrahippocampal infusion of the MEK inhibitors PD98059 and U0126. Both compounds are selective for MEK relative to related kinases, as assessed in cell-free assays, cell cultures, and intact hippocampal tissue (Alessi et al., 1995; English and Sweatt, 1997; Favata et al., 1998). MEK inhibitors were applied at a concentration $(30 \mu \mathrm{M})$ that inhibits ERK activation in the hippocampal slice.

BDNF was infused immediately above the dentate gyrus, $\sim 300$ $\mu \mathrm{m}$ dorsal to the synaptic zone of medial perforant path fibers. As shown in Figure $1 A$, BDNF inf usion $(2 \mu \mathrm{g} / 2 \mu \mathrm{l}, 25 \mathrm{~min})$ led to a robust increase in the slope of the fEPSP and in the amplitude of the population spike. fEPSP values were significantly elevated above baseline at $15 \min (p<0.05 ; n=16)$ (Fig. $1 A)$, climbed gradually to a stable plateau at 3-4 hr after BDNF infusion (Fig. 2 ), and persisted without decrement for as long as we recorded (maximum of $15 \mathrm{hr}$; data not shown). Infusion of PD98059 (30 $\mu \mathrm{M} ; n=8)$ for $10 \mathrm{~min}$ before and during infusion of BDNF completely abolished this potentiation (Fig. $1 A)$. U0126 (30 $\mu \mathrm{M}$; $n=8$ ), a structurally and mechanistically distinct MEK inhibitor, also completely blocked development of BDNF-LTP (Fig. 1B). Cytochrome $c$, a protein similar to BDNF in molecular weight and charge, was used to control for possible nonspecific effects of protein infusion. Figure $1 C$ shows that synaptic transmission 

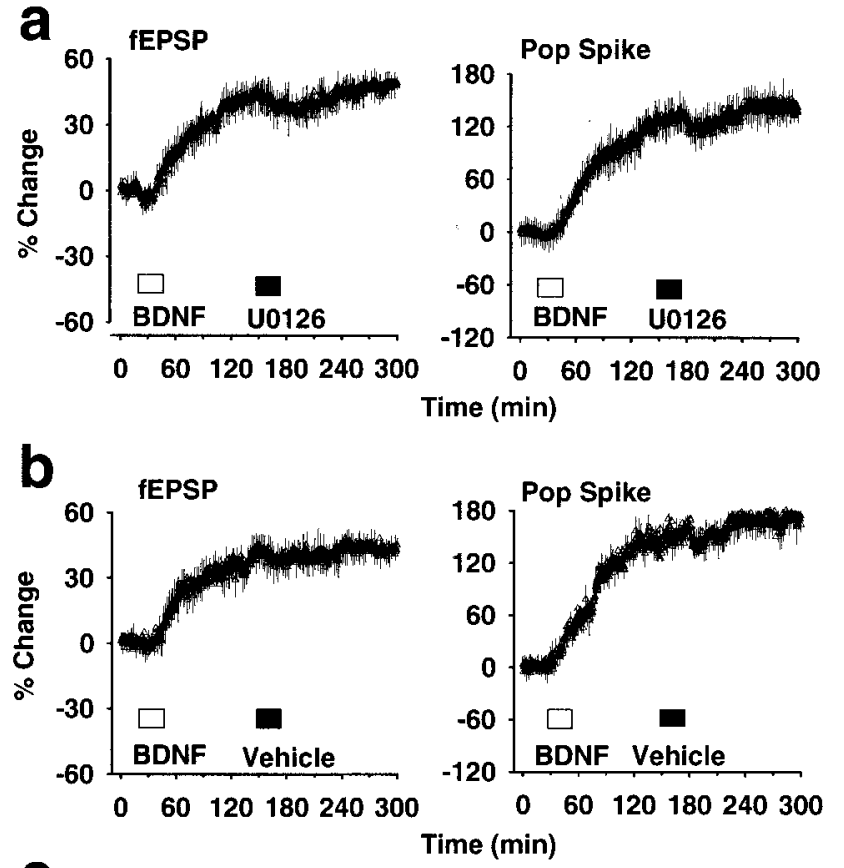

C

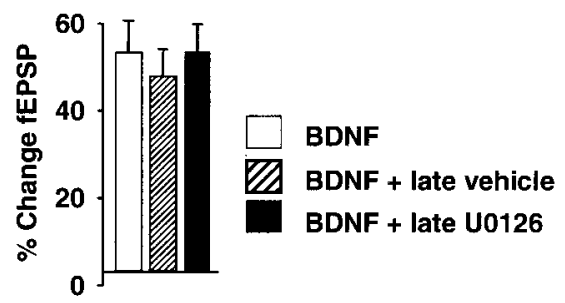

Figure 2. Effect of the MEK inhibitor U0126 on established BDNFLTP. $a$, U0126 $(30 \mu \mathrm{M}, 2 \mu \mathrm{l})$ was infused 110 min after BDNF infusion, during established BDNF-LTP. MEK inhibitor treatment had no significant effect on medial perforant path-evoked responses during infusion or during the subsequent $2 \mathrm{hr}$ recording period. $n=6 . b$, Effect of vehicle (DMSO-PBS) infusion on established BDNF-LTP. $n=6$. $c$, Summary bar graph of fEPSP slope increases obtained in groups receiving BDNF alone or BDNF and post-treatment with U0126 or PBS. Values are group means + SEM) based on 20 responses collected at the end of recording, 245-255 min after BDNF infusion. $n=6$ in all groups. There was no significant difference between groups in the magnitude of BDNF-LTP $(p>0.05)$.

remained stable after cytochrome $c$ infusion $(n=8 ; p>0.05)$. Infusion of PD98059 $(n=6)$ or U0126 $(n=4)$ alone also had no significant effect on baseline transmission (Fig. 1D). The complete block of BDNF-LTP development by two different MEK inhibitors indicates a requirement for ERK activation in BDNFLTP. Furthermore, the results suggest that maintenance of baseline synaptic efficacy is not dependent on constitutive activation of ERK through MEK.

\section{MEK activation is not required for the expression of BDNF-LTP}

The kinetics of BDNF inactivation is not well known, but BDNF is a sticky protein, and tissue clearance is relatively slow. If BDNF is retained in the extracellular space, the observed increase in synaptic efficacy might be attributable to repetitive activation of TrkB rather than induction of a plastic change. To address this issue, U0126 was applied during established BDNFLTP, 2 hr after BDNF infusion. U0126, applied at a concentration that eliminates BDNF-LTP development, had no effect when applied after BDNF-LTP was established (Fig. 2A). Statistical analysis was performed on fEPSP slope values obtained immediately before, immediately after, and $2 \mathrm{hr}$ after U0126 infusion $(p<0.05 ; n=6)$. Treatment with the MEK inhibitor vehicle PBS-DMSO also had no significant effect on established BDNFLTP $(n=4)$ (Fig. $2 B)$. The magnitude of the fEPSP slope increase in rats receiving U0126 or vehicle after treatment was not significantly different from time-matched controls receiving BDNF alone $(p>0.05)$ (Fig. $2 C)$. We conclude that (1) BDNF acts rapidly through ERK to induce a long-term increase in synaptic efficacy and (2) ERK activation through MEK is not required for expression of the potentiated state.

\section{BDNF-LTP triggers rapid activation of ERK and p38 but not JNK}

Next we sought to determine the time course of ERK phosphorylation. We also examined two additional MAPK family members, p38 kinase (or SAPK2) and JNK (or SAPK1). Homogenates from microdissected dentate gyrus and hippocampal regions CA1 and CA3 were prepared at $15 \mathrm{~min}$ and $3 \mathrm{hr}$ after BDNF inf usion and subjected to Western blotting. Densitometric analysis of phospho-ERK2 showed significantly elevated levels at $15 \mathrm{~min}(n=8)$ and $3 \mathrm{hr}(n=7)$ in the inf used dentate gyrus (Fig. $3 A, B)$. No changes in ERK2 phosphorylation were detected in the CA1 and CA3 fields. Treatment with U0126 blocked both the increase in ERK2 phosphorylation (Fig. $3 A, B$ ) and the development of BDNF-LTP at $15 \mathrm{~min}$ and $3 \mathrm{hr}(n=4$ at both time points) (Fig. $3 C$ ). The results confirm a rapid activation of ERK in response to BDNF and verify the efficacy of MEK inhibitors in blocking ERK activation. Figure 4 shows the effect of BDNF on p38 and JNK phosphorylation. Interestingly, ERK2 activation was paralleled by activation of p38 at $15 \mathrm{~min}$ and $3 \mathrm{hr}$ in the infused dentate gyrus, whereas JNK phosphorylation was unaffected. Control infusions with cytochrome $c$ had no effect on ERK, p38, or JNK activity (Figs. 3A, 4A). Total protein levels for these kinases were monitored throughout and were found to be unchanged across treatments and hippocampal regions. A representative blot in Figure $3 B$ shows the lack of effect of BDNF on total ERK1/2 protein levels in all hippocampal regions.

\section{ERK-dependent CREB activation}

ERK activation leading to phosphorylation of CREB at Ser-133 and the expression of CRE-driven genes is implicated in the formation of late phase LTP (Impey et al., 1998; Davis et al., 2000), and BDNF acts through CREB in the regulation of early gene expression in hippocampal cell cultures (Finkbeiner et al., 1997). We therefore asked whether BDNF-induced LTP is associated with CREB activation. As shown in Figure 5, CREB Ser ${ }^{133}$ phosphorylation in the infused dentate gyrus was enhanced 15 min after BDNF infusion and returned to control levels at $3 \mathrm{hr}$. This rapid activation of CREB was abolished by the MEK inhibitor U0126. Thus, BDNF signaling through ERK is required for CREB phosphorylation and induction of BDNF-LTP in vivo.

\section{ERK-dependent upregulation of Arc expression}

HFS-LTP is associated with the induction of calcium-regulated immediate early genes encoding Arc and Zif268 (Cole et al., 1989; Wisden et al., 1990; Link et al., 1995; Lyford et al., 1995). Both genes are required for the full development of late LTP and long-term memory consolidation (Guzowski et al., 2000; Jones et al., 2001). If exogenous BDNF stimulates the generation of late LTP, one or both of these critical genes should be induced. We first used immunoblotting to determine the effect of BDNF-LTP 
a

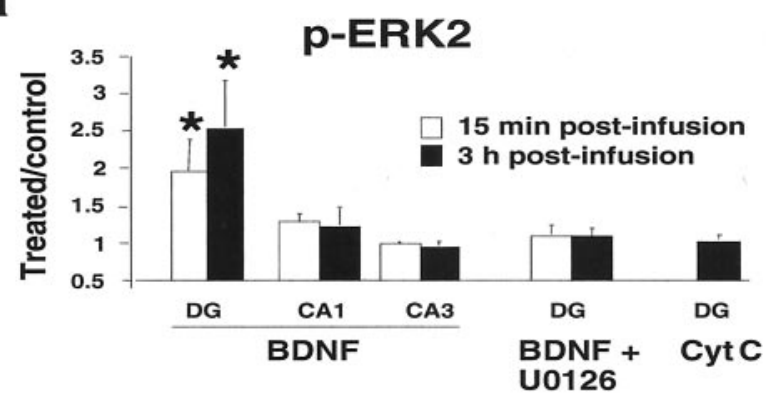

b
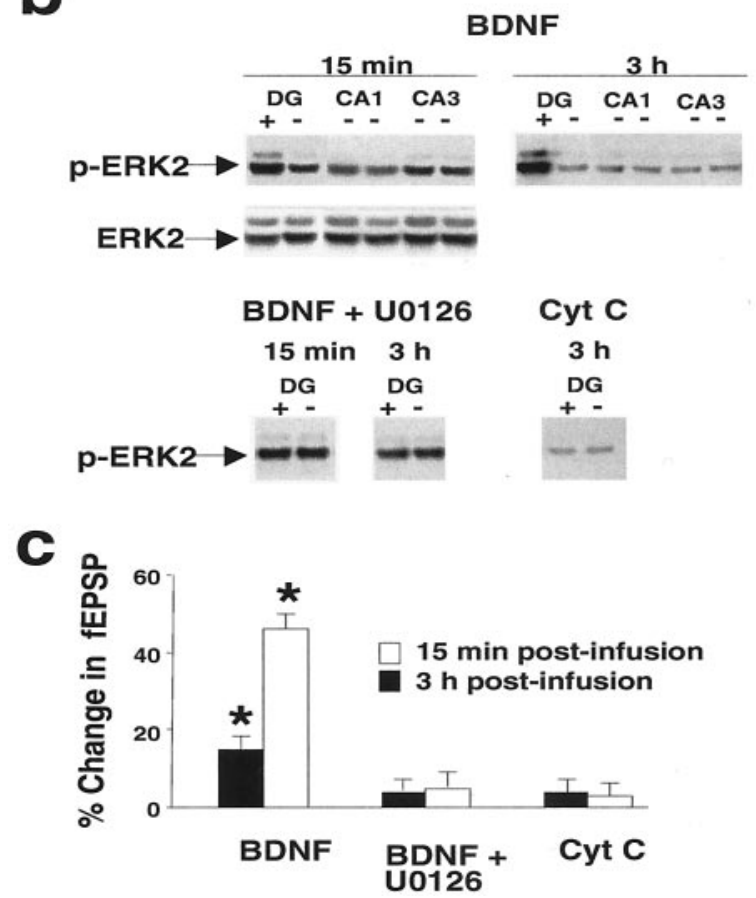

Figure 3. BDNF-LTP is coupled to enhanced ERK phosphorylation in the dentate gyrus. Western blot assays of phosphorylated, active ERK (p-ERK1/2) were run on aliquoted samples from microdissected dentate gyrus $(D G)$ and hippocampal regions CA1 and CA3 after in vivo electrophysiological experiments. $a$, Group mean + SEM changes in p-ERK2 immunoreactivity levels based on densitometric analysis. Optical density values are expressed as a ratio between the treated and nontreated (control) side for each hippocampal subfield. BDNF infusion increased activation of ERK2 at $15 \mathrm{~min}(n=8)$ and $3 \mathrm{hr}(n=7)$ in the infused dentate gyrus. BDNF had no effect on ERK2 phosphorylation in hippocampal region CA1 or CA3. Delivery of the MEK inhibitor U0126 abolished the increase in ERK2 phosphorylation at both $15 \mathrm{~min}$ and $3 \mathrm{hr}$. $n=4$ at both time points. Cytochrome $c(C y t C)$ infusion had no effect on p-ERK2 immunoreactivity levels. ${ }^{*} p<0.05$, significant difference from control. $b$, Representative p-ERK immunoblots for the group data shown in $a$. Total ERK2 protein levels were unchanged. $c$, Bar graph of the fEPSP slope changes obtained at $15 \mathrm{~min}$ and $3 \mathrm{hr}$ after inf usion. ${ }^{*} p<0.05$, significant difference from baseline.

on Arc and Zif268 protein expression. As illustrated in Figure 6, $A$ and $B, \mathrm{BDNF}$ led to a threefold elevation in $A r c$ protein levels at $3 \mathrm{hr}$ in the inf used dentate gyrus. Blockade of BDNF-LTP with U0126 completely abolished the increase in Arc protein expression. In contrast, BDNF had no effect on Zif268 levels in the dentate gyrus or other hippocampal regions at the same time point $(3 \mathrm{hr})$. The possibility that we missed a time window of Zif268 regulation is unlikely, because Arc and Zif268 show similar activation kinetics after HFS-LTP, with strong upregulation a
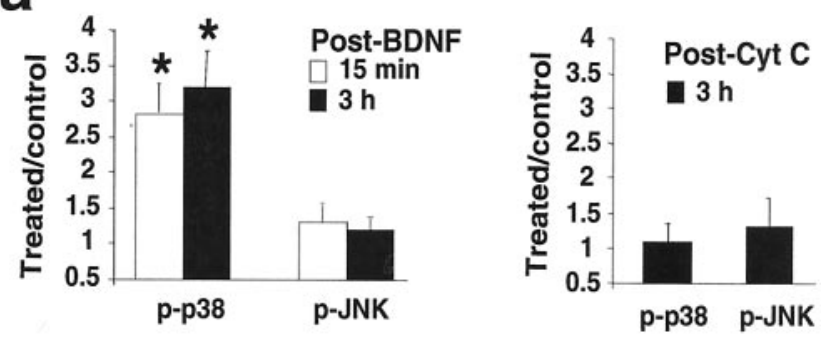

b

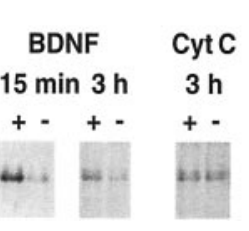

Figure 4. BDNF-LTP is associated with enhanced activation of p38 MAPK but not JNK. $a$, Group mean + SEM changes in phosphorylated kinase immunoreactivity levels based on densitometric analysis. Optical density values are expressed as a ratio between the treated and nontreated (control) dentate gyrus. BDNF infusion increased phospho-p38 immunoreactivity at $15 \mathrm{~min}(n=8)$ and $3 \mathrm{hr}(n=7)$ in the infused dentate gyrus. BDNF infusion had no effect on JNK phosphorylation. Cytochrome $c(C y t C)$ infusion had no effect on p-p38 or p-JNK immunoreactivity levels. There were no changes in phosphorylation of these kinases in region CA1 or CA3 (data not shown). Total protein levels of p38 and JNK were unchanged in all hippocampal regions across treatments. ${ }^{*} p<$ 0.05 , significant difference from control. $b$, Representative Western blots for group data shown in $a$.
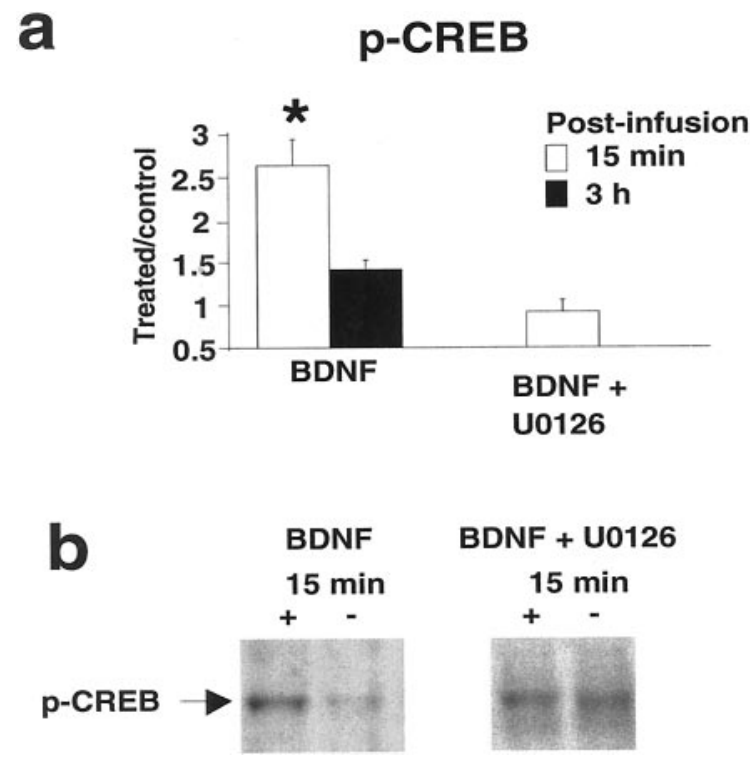

Figure 5. BDNF-LTP is coupled to rapid CREB phosphorylation. $a$, Group mean + SEM changes in p-CREB immunoreactivity levels based on densitometric analysis. CREB-Ser ${ }^{133}$ was rapidly phosphorylated at 15 min $(n=8)$, returning to control levels at $3 \mathrm{hr}(n=7)$ after BDNF infusion. Infusion of the U0126 blocked CREB activation. ${ }^{*} p<0.05$, significant difference from control. $b$, p-CREB Western blots for group data in $a$.

of Zif268 protein between $30 \mathrm{~min}$ and at least $4 \mathrm{hr}$ after HFS (Richardson et al., 1992).

Next we performed in situ hybridization histochemistry to assess the expected transcriptional activation of $A r c$ and to gain insight into the cellular localization of $A r c$ regulation in the 

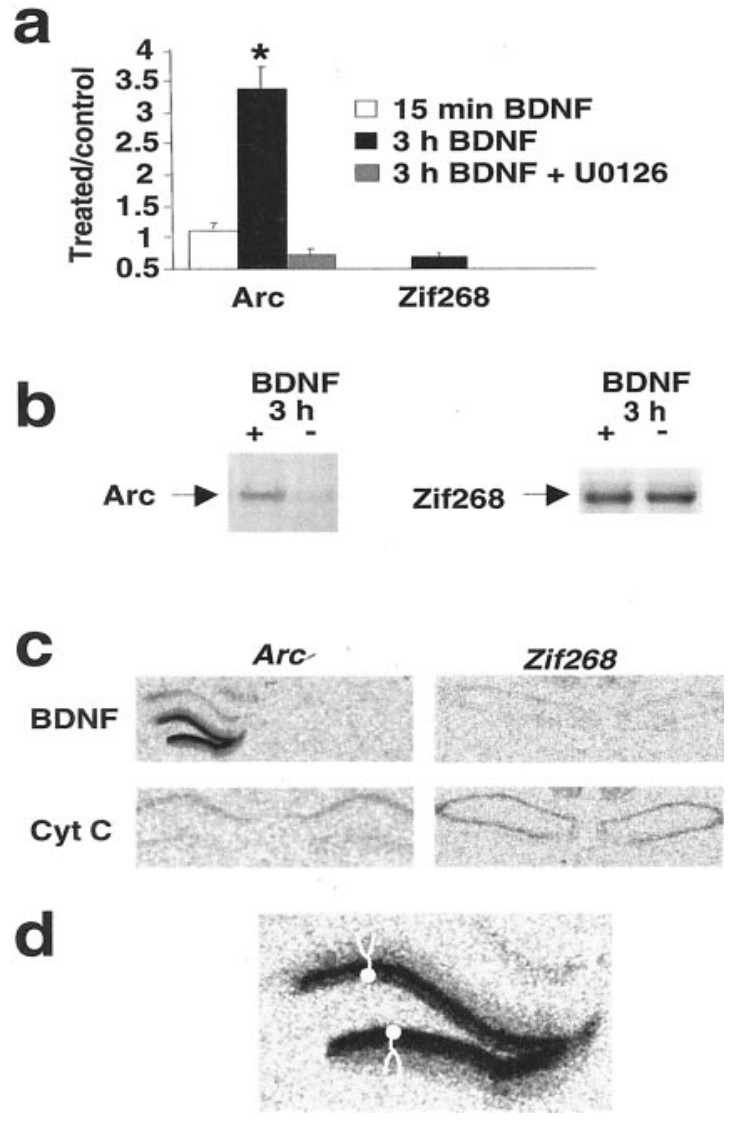

Figure 6. BDNF-LTP is coupled to upregulation of Arc mRNA and protein. $a$, Group mean + SEM changes in Arc and Zif268 protein immunoreactivity levels. Arc protein expression was increased at $3 \mathrm{hr}(n=$ $7)$, but not $15 \mathrm{~min}(n=8)$, after BDNF infusion. These increases were confined to the infused dentate gyrus. U0126 blocked the increases in Arc expression. BDNF infusion had no effect on Zif268 protein expression. ${ }^{*} p<0.05$, significant difference from control. $b$, Representative Western blots for group data in $a$. $c$, Autoradiographs showing in situ hybridization signals for Arc and Zif268 in the hippocampus $2 \mathrm{hr}$ after BDNF or cytochrome $c$ infusion into the left dentate gyrus. Note the robust increase in the hybridization signal for $\operatorname{Arc}$ mRNA in the treated dentate gyrus. $d$, High-magnification autoradiographic image of the Arc mRNA signal in the dentate gyrus. Model granule cells with apical dendrites extending throughout the molecular layer are depicted in the top and bottom blades of the dentate gyrus. Arc mRNA is strongly upregulated in granule cell bodies and extensively distributed in granule cells dendrites.

dentate gyrus. Brains for in situ hybridization were obtained $2 \mathrm{hr}$ after infusion with BDNF or cytochrome $c$. Arc mRNA levels were powerfully upregulated in the granule cell layer and the throughout the molecular layer of the dentate gyrus, indicating extensive dendritic delivery of $A r c$ transcripts from granule cell somata into dendrites (Fig. $6 C, D$ ). Consistent with the protein expression data, BDNF infusion had no effect on Zif 268 mRNA levels in the dentate gyrus. These results link BDNF-LTP to ERK-dependent induction of Arc gene expression and protein synthesis in granule cells.

\section{DISCUSSION}

Current evidence suggests that BDNF released during or shortly after HFS plays an obligatory role in the generation of late LTP in the CA1 region of the hippocampal slice. Maintenance of LTP beyond 1-2 hr is relatively selectively impaired by treatment with the BDNF scavenger TrkB-Fc, treatment with function blocking antibodies to BDNF or TrkB, constitutive deletion of a BDNF allele, or conditional deletion of the TrkB gene (Figurov et al., 1996; Patterson et al., 1996; Kang et al., 1997; Korte et al., 1998; Chen et al., 1999; Minichiello et al., 1999).

The present study is the first to explore BDNF mechanisms in long-term synaptic plasticity in vivo. We show that locally applied BDNF triggers a long-term potentiation (BDNF-LTP) at medial perforant path-granule synapses, the induction of which (but not the maintenance) requires MEK-ERK activation. We also found that BDNF-LTP is associated with ERK-dependent activation of CREB and upregulation of the immediate early gene Arc. ERK and CREB have emerged as critical points of convergence in the signaling pathways regulating gene transcription in late LTP and long-term memory (Atkins et al., 1998; Impey et al., 1998; Davis et al., 2000). Inhibition of $A r c$ mRNA translation after injection of antisense oligonucleotides impairs late LTP and long-term memory consolidation, leaving LTP induction and memory acquisition intact (Guzowski et al., 2000). The present data show that BDNF triggers synaptic strengthening and activates a set of cellular events obligatory to development of late LTP and long-term memory.

HFS-LTP experiments have shown that Arc induction is NMDA receptor dependent, but the signal transduction pathways underlying Arc induction are unknown (Link et al., 1995; Lyford et al., 1995; Steward et al., 1998). The possibility that BDNF induces LTP indirectly by stimulating glutamate release and NMDA receptor activation can be ruled out because NMDA receptor blockers have no effect on BDNF-LTP in the CA1 region in vitro or dentate gyrus in vivo (Kang and Schuman, 1995; Messaoudi et al., 2000). Our results implicate BDNF as an important regulator of $A r c$ induction in long-term synaptic plasticity in vivo and demonstrate a requirement for MEK-ERK in the process. Very little information is available on Arc function at present, although roles in cytoskeletal reorganization and regulation of calcium/calmodulin-dependent kinase II localization in dendrites have been proposed (Guzowski et al., 2000). Previous in vitro work has identified $\mathrm{CREB}$ as a major mediator of BDNF responses (Finkbeiner et al., 1997; Pizzorusso et al., 2000; Iida et al., 2001). Our results extend this observation to BDNF regulation of synaptic plasticity in vivo. A causal role for CREB and Arc remains to be established, although the parallels to late LTP mechanisms are striking.

A recent study in Zif268 knock-out mice showed that this gene is required for late LTP (as measured 2 and $3 \mathrm{~d}$ after HFS) and hippocampal-dependent long-term memory (Jones et al., 2001). If BDNF launches late LTP, why does it not activate Zif268? The simplest explanation is that Arc and Zif268 mediate separable components of mRNA synthesis-dependent LTP (Fig. 7). This is consistent with the different kinetics of Arc and Zif268 function; Arc mRNA is delivered to dendrites and translated within minutes after HFS, followed by delayed, if overlapping, expression of Zif268-regulated late response genes. Arc antisense experiments support an early role for $A r c$, because treated animals show impaired LTP as early as $4 \mathrm{hr}$ after HFS. In seeking to dissect the components of late LTP, exogenous BDNF-LTP should provide a useful tool for exploring the Arc effector pathway.

The phenomenon of BDNF-LTP is controversial in the CA1 region in hippocampal slices in which high rates of BDNF perfusion are necessary (Kang et al., 1996). In the present in vivo study, BDNF was applied as a concentrated bolus. The question may be asked whether exogenous application is physiologically relevant. Two lines of evidence support a functional role. First, in 


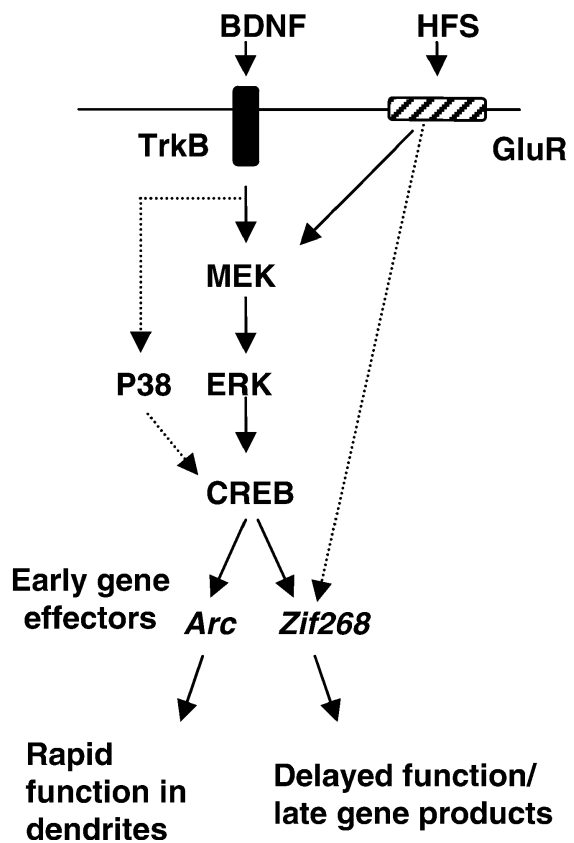

Figure 7. Model of BDNF signaling pathways underlying BDNF-LTP in the dentate gyrus in vivo. Exogenous application of BDNF triggers LTP through activation of MEK-ERK. ERK activation is required for both CREB phosphorylation and induction of the immediate early gene Arc in dentate granule cells. Arc and Zif268 are both required in late HFS-LTP (Guzowski et al., 2000; Jones et al., 2001), yet they are likely to mediate distinct components of the process; Arc is rapidly delivered to dendrites and translated, whereas Zif 268 regulates expression of delayed response genes. Our data suggests the hypothesis that BDNF triggers late LTP through ERK-dependent induction of Arc. HFS must recruit additional pathways to induce Zif268 expression, leading to transcription of late effector genes and full expression of late LTP.

triggering mechanisms critical to late LTP, exogenous BDNF mimics the predicted actions of endogenous BDNF. Second, BDNF-LTP occludes with late LTP in the CA1 region in vitro and in the dentate gyrus in vivo, indicating common mechanisms of expression (Kang et al., 1997; Messaoudi et al., 2000). The difficulty in obtaining BDNF-LTP in slices may be related to the difficulty in accessing (and rapidly activating) signal transducing TrkB receptors at excitatory synapses. Access to the synaptic cleft is strongly inhibited by truncated (noncatalytic) TrkB receptors on glial cells and dendritic shafts, and expression of truncated TrkB is strongly upregulated in adulthood (Biffo et al., 1995; Eide et al., 1996; Drake et al., 1999). We suggest that acute, local delivery of a BDNF saturates the truncated TrkB system, allowing activation of synaptic TrkB.

The MEK inhibitor experiments identify a time window of rapid ERK activation critical for BDNF-LTP induction. U0126 blocked BDNF-LTP when applied together with BDNF but had no effect if applied $2 \mathrm{hr}$ later. Interestingly, the time course of ERK phosphorylation was both rapid and sustained. What is the function of the sustained increase in ERK activity? One possibility is that it mediates delayed gene expression responses that come into play at a later stage, beyond the recording period used here. In PC12 cells, NGF induces a sustained ERK activity that is critical for gene induction responses leading to neuronal differentiation (Marshall, 1995; Xing et al., 1998). In this system, ERK is persistently activated after the formation of a stable upstream complex between the small G-protein Rap-1 and B-raf, an MEK activator (York et al., 1998). Alternatively, ERK may be retained in a constitutively activated state after its dimerization and nuclear translocation (Impey et al., 1998; Grewal et al., 1999). ERK is rapidly activated in response to HFS-LTP in the CA1 region (English and Sweatt, 1996, 1997; Impey et al., 1998) and dentate gyrus (Coogan et al., 1999; Maguire et al., 1999; Davis et al., 2000; Rosenblum et al., 2000). Most studies have focussed on relatively early time points, and it is not yet clear whether sustained ERK activation occurs. However, hippocampal-dependent learning is associated with a period of long-lasting ERK activation (Atkins et al., 1998), and sustained ERK activity is coupled to structural plasticity of dendrites in cultured hippocampal neurons (Wu et al., 2001).

BDNF-LTP was coupled to a parallel activation of ERK and p38 MAPK. Recent data suggests a broad range of physiological functions for p38 in processes such as long-term depression, cytoskeletal reorganization, and cell proliferation (Matsumoto et al., 1999; Bolshakov et al., 2000), in addition to its common association with pathophysiological processes such as inflammation and neurodegeneration. The p38 activation observed here cannot be attributed to nonspecific effects of infusion because infusion with a control protein, cytochrome $c$, had no effect on p38 activation (or activation of any of the other kinases examined). Furthermore, BDNF and cytochrome $c$ had no effect on JNK, the MAPK family member most strongly implicated in neurodegeneration and apoptosis. Xing et al. (1998) have identified a pathway in PC12 cells that may be involved. They found that NGF activates a bifurcated pathway from Ras leading to dual activation of ERK and p38. ERK and p38 then converge through distinct CREB kinases to activate CREB and trigger immediate early gene transcription.

The rapid onset of BDNF-LTP (it was significant 40 min after starting BDNF infusion) seems incompatible with a process dependent solely on gene expression. ERK has many potential cytosolic substrates, however, and several rapid ERK-dependent mechanisms could be involved (Grewal et al., 1999). One intriguing scenario is that ERK and p38 stimulate protein synthesis at the post-transcriptional level through activation of the Ser/Thr kinase Mnk1 and subsequent phosphorylation of eukaryotic initiation factor 4E (Sonenberg and Gingras, 1998). In the hippocampal CA1 region, BDNF is thought to enhance synaptic efficacy by stimulating translation of dendritically localized mRNA (Kang and Schuman, 1996). Translation activation in dendrites would precede transcriptional events, going hand-inhand with the arrival of Arc mRNA in dendrites.

Catalytic TrkB is located on axon terminals and dendritic spines of glutamate synapses and to a lesser extent on terminals of interneurons and extrinsic modulatory inputs (Drake et al., 1999; Aoki et al., 2000). Presynaptically, BDNF can acutely enhance glutamate release and attenuate synaptic fatigue in response to HFS (Gottschalk et al., 1998, 1999; Jovanovic et al., 2000; Schinder and Poo, 2000; Xu et al., 2000). Although BDNF clearly functions as a presynaptic modulator, postsynaptic actions, including new mRNA and protein synthesis, are likely to underlie long-term synaptic plasticity. The present data showing ERKdependent activation of the nuclear transcription factor CREB and upregulation of $A r c$ mRNA in granule cells clearly supports a postsynaptic mechanism.

In a recent review, Schinder and Poo (2000) asked whether neurotrophins play an "instructive" role in LTP by inducing synaptic potentiation or a "permissive" role by maintaining housekeeping functions that are necessary for the induction and maintenance of LTP. Our findings support an instructive role in 
which BDNF triggers a consolidation process underlying stable synaptic strengthening.

\section{REFERENCES}

Aakalu G, Smith WB, Nguyen N, Jiang C, Schuman EM (2001) Dynamic visualization of local protein synthesis in hippocampal neurons. Neuron 30:489-502.

Alessi DR, Cuenda A, Cohen P, Dudley DT, Saltiel AR (1995) PD 098059 is a specific inhibitor of the activation of mitogen-activated protein kinase kinase in vitro and in vivo. J Biol Chem 270:27489-27494.

Aoki C, Wu K, Elste A, Len G, Lin S, McAuliffe G, Black IB (2000) Localization of brain-derived neurotrophic factor and TrkB receptors to postsynaptic densities of adult rat cerebral cortex. J Neurosci Res 59:454-463.

Atkins CM, Selcher JC, Petraitis JJ, Trzaskos JM, Sweatt JD (1998) The MAPK cascade is required for mammalian associative learning. Nat Neurosci 1:602-609.

Bibel M, Barde YA (2000) Neurotrophins key regulators of cell fate and cell shape in the vertebrate nervous system. Genes Dev 14:2919-2937.

Biffo S, Offenhauser N, Carter BD, Barde YA (1995) Selective binding and internalisation by truncated receptors restrict the availability of BDNF during development. Development 121:2461-2470.

Bliss TV, Collingridge GL (1993) A synaptic model of memory: longterm potentiation in the hippocampus. Nature 361:31-39.

Bolshakov VY, Carboni, L, Siegelbaum SA, Belardetti F (2000) Dual MAP kinase pathways mediate opposing forms of long-term plasticity at CA3-CA1synapses. Nat Neurosci 3:1107-1112.

Chen G, Kolbeck R, Barde YA, Bonhoeffer T, Kossel A (1999) Relative contribution of endogenous neurotrophins in hippocampal long-term potentiation. J Neurosci 19:7983-7990.

Cole AJ, Saffen DW, Baraban JM, Worley PF (1989) Rapid increase of an immediate early gene messenger RNA in hippocampal neurons by synaptic NMDA receptor activation. Nature 340:474-476.

Coogan AN, O'Leary DM, O'Connor JJ (1999) P42/44 MAP kinase inhibitor PD 98059 attenuates multiple forms of synaptic plasticity in rat dentate gyrus in vitro. J Neurophysiol 81:103-110.

Crozier RA, Black IB, Plummer MR (1999) Blockade of NR2Bcontaining NMDA receptors prevents BDNF enhancement of glutamatergic transmission in hippocampal neurons. Learn Mem 6:257-266.

Davis S, Vanhoutte P, Pages C, Caboche J, Laroche S (2000) The MAPK/ERK cascade targets both Elk-1, cAMP response elementbinding protein to control long-term potentiation-dependent gene expression in the dentate gyrus in vivo. J Neurosci 20:4563-4572.

Drake CT, Milner TA, Patterson SL (1999) Ultrastructural localization of full-length trkB immunoreactivity in rat hippocampus suggests multiple roles in modulating activity-dependent synaptic plasticity. J Neurosci 19:8009-8026.

Eide FF, Vining ER, Eide BL, Zang K, Wang XY, Reichardt LF (1996) Naturally occurring truncated trkB receptors have dominant inhibitory effects on brain-derived neurotrophic factor signaling. J Neurosci 16:3123-3129.

English JD, Sweatt JD (1996) Activation of p42 mitogen-activated protein kinase in hippocampal long term potentiation. J Biol Chem 271:24329-24332.

English JD, Sweatt JD (1997) A requirement for the mitogen-activated protein kinase cascade in hippocampal long term potentiation. J Biol Chem 272:19103-19106.

Favata MF, Horiuchi KY, Manos EJ, Daulerio AJ, Stradley DA, Feeser WS, Van Dyk DE, Pitts WJ, Earl RA, Hobbs F, Copeland RA, Magolda RL, Scherle PA, Trzaskos JM (1998) Identification of a novel inhibitor of mitogen-activated protein kinase kinase. J Biol Chem 273:18623-18632.

Figurov A, Pozzo Miller LD, Olafsson P, Wang T, Lu B (1996) Regulation of synaptic responses to high-frequency stimulation and LTP by neurotrophins in the hippocampus. Nature 381:706-709.

Finkbeiner S, Tavazoie SF, Maloratsky A, Jacobs KM, Harris KM, Greenberg ME (1997) CREB: a major mediator of neuronal neurotrophin responses. Neuron 19:1031-1047.

Frerking M, Malenka RC, Nicoll RA (1998) Brain-derived neurotrophic factor (BDNF) modulates inhibitory, but not excitatory, transmission in the CA1 region of the hippocampus. J Neurophysiol 80:3383-3386.

Gottschalk W, Pozzo-Miller LD, Figurov A, Lu B (1998) Presynaptic modulation of synaptic transmission and plasticity by brain-derived neurotrophic factor in the developing hippocampus. J Neurosci 18:6830-6839.

Gottschalk WA, Jiang H, Tartaglia N, Feng L, Figurov A, Lu B (1999) Signaling mechanisms mediating BDNF modulation of synaptic plasticity in the hippocampus. Learn Mem 6:243-256.

Grewal SS, York RD, Stork PJ (1999) Extracellular-signal-regulated kinase signalling in neurons. Curr Opin Neurobiol 9:544-553.
Guzowski JF, Lyford GL, Stevenson GD, Houston FP, McGaugh JL, Worley PF, Barnes CA (2000) Inhibition of activity-dependent arc protein expression in the rat hippocampus impairs the maintenance of long-term potentiation and the consolidation of long-term memory. J Neurosci 20:3993-4001.

Iida N, Namikawa K, Kiyama H, Ueno H, Nakamura S, Hattori S (2001) Requirement of Ras for the activation of mitogen-activated protein kinase by calcium influx, cAMP, and neurotrophin in hippocampal neurons. J Neurosci 21:6459-6466.

Impey S, Mark M, Villacres EC, Poser S, Chavkin C, Storm DR (1996) Induction of CRE-mediated gene expression by stimuli that generate long-lasting LTP in area CA1 of the hippocampus. Neuron 16:973-982.

Impey S, Obrietan K, Wong ST, Poser S, Yano S, Wayman G, Deloulme JC, Chan G, Storm DR (1998) Cross talk between ERK and PKA is required for $\mathrm{Ca}^{2+}$ stimulation of CREB-dependent transcription and ERK nuclear translocation. Neuron 21:869-883.

Jones MW, Errington ML, French PJ, Fine A, Bliss TV, Garel S, Charnay P, Bozon B, Laroche S, Davis S (2001) A requirement for the immediate early gene Zif268 in the expression of late LTP and long-term memories. Nat Neurosci 4:289-296.

Jovanovic JN, Czernik AJ, Fienberg AA, Greengard P, Sihra TS (2000) Synapsins as mediators of BDNF-enhanced neurotransmitter release. Nat Neurosci 3:323-329.

Kang H, Schuman EM (1995) Long-lasting neurotrophin-induced enhancement of synaptic transmission in the adult hippocampus. Science 267:1658-1662.

Kang H, Schuman EM (1996) A requirement for local protein synthesis in neurotrophin-induced hippocampal synaptic plasticity. Science 273:1402-1406.

Kang H, Welcher AA, Shelton D, Schuman EM (1997) Neurotrophins and time: different roles for TrkB signaling in hippocampal long-term potentiation. Neuron 19:653-664.

Kang HJ, Jia LZ, Suh K-Y, Tang L, Schuman EM (1996) Determinants of BDNF-induced hippocampal synaptic plasticity: role of the Trk B receptor and the kinetics of neurotrophin delivery. Learn Mem 3:188-196.

Kaplan DR, Miller FD (2000) Neurotrophin signal transduction in the nervous system. Curr Opin Neurobiol 10:381-391.

Korte M, Kang H, Bonhoeffer T, Schuman EM (1998) A role for BDNF in the late-phase of hippocampal long-term potentiation. Neuropharmacology 37:553-559.

Lessmann V, Heumann R (1998) Modulation of unitary glutamatergic synapses by neurotrophin- $4 / 5$ or brain-derived neurotrophic factor in hippocampal microcultures: presynaptic enhancement depends on preestablished paired-pulse facilitation. Neuroscience 86:399-413.

Li YX, Xu Y, Ju D, Lester HA, Davidson N, Schuman EM (1998) Expression of a dominant negative TrkB receptor, T1, reveals a requirement for presynaptic signaling in BDNF-induced synaptic potentiation in cultured hippocampal neurons. Proc Natl Acad Sci USA 95:10884-10889.

Link W, Konietzko U, Kauselmann G, Krug M, Schwanke B, Frey U, Kuhl D (1995) Somatodendritic expression of an immediate early gene is regulated by synaptic activity. Proc Natl Acad Sci USA 92:5734-5738.

Lyford GL, Yamagata K, Kaufmann WE, Barnes CA, Sanders LK, Copeland NG, Gilbert DJ, Jenkins NA, Lanahan AA, Worley PF (1995) Arc, a growth factor and activity-regulated gene, encodes a novel cytoskeleton-associated protein that is enriched in neuronal dendrites. Neuron 14:433-445.

Maguire C, Casey M, Kelly A, Mullany PM, Lynch MA (1999) Activation of tyrosine receptor kinase plays a role in expression of long-term potentiation in the rat dentate gyrus. Hippocampus 9:519-526.

Marshall CJ (1995) Specificity of receptor tyrosine kinase signaling: transient versus sustained extracellular signal-regulated kinase activation. Cell 80:179-185.

Matsumoto T, Yokote K, Tamura K, Takemoto M, Ueno H, Saito Y, Mori S (1999) Platelet-derived growth factor activates p38 mitogenactivated protein kinase through a Ras-dependent pathway that is important for actin reorganization and cell migration. J Biol Chem 274:13954-13960.

Messaoudi E, Bardsen K, Srebro B, Bramham CR (1998) Acute intrahippocampal inf usion of BDNF induces lasting potentiation of synaptic transmission in the rat dentate gyrus. J Neurophysiol 79:496-499.

Messaoudi, E, Croll SD, Bramham CR (2000) Characterization of BDNF-induced long-term potentiation in the rat dentate gyrus. Soc Neurosci Abstr 26:247.

Milbrandt J (1987) A nerve growth factor-induced gene encodes a possible transcriptional regulatory factor. Science 238:797-799.

Minichiello L, Korte M, Wolfer D, Kuhn R, Unsicker K, Cestari V, Rossi AC, Lipp HP, Bonhoeffer T, Klein R (1999) Essential role for TrkB receptors in hippocampus-mediated learning. Neuron 24:401-414.

Nguyen PV, Kandel ER (1996) A macromolecular synthesis-dependent late phase of long-term potentiation requiring cAMP in the medial perforant pathway of rat hippocampal slices. J Neurosci 16:3189-3198.

Patterson SL, Abel T, Deuel TA, Martin KC, Rose JC, Kandel ER (1996) 
Recombinant BDNF rescues deficits in basal synaptic transmission and hippocampal LTP in BDNF knockout mice. Neuron 16:1137-1145.

Pizzorusso T, Ratto GM, Putignano E, Maffei L (2000) Brain-derived neurotrophic factor causes cAMP response element-binding protein phosphorylation in absence of calcium increases in slices and cultured neurons from rat visual cortex. J Neurosci 20:2809-2816.

Richardson CL, Tate WP, Mason SE, Lawlor PA, Dragunow M, Abraham WC (1992) Correlation between the induction of an immediate early gene, zif $/ 268$, and long-term potentiation in the dentate gyrus. Brain Res 580:147-154.

Rosenblum K, Futter M, Jones M, Hulme EC, Bliss TV (2000) ERKI/II regulation by the muscarinic acetylcholine receptors in neurons $\mathrm{J}$ Neurosci 20:977-985.

Schinder AF, Poo MM (2000) The neurotrophin hypothesis for synaptic plasticity. Trends Neurosci 23:639-645.

Schuman EM (1999) Neurotrophin regulation of synaptic transmission. Curr Opin Neurobiol 9:105-109.

Sonenberg N, Gingras AC (1998) The mRNA 5' cap-binding protein eIF4E and control of cell growth. Curr Opin Cell Biol 10:268-275.

Song HJ, Poo MM (1999) Signal transduction underlying growth cone guidance by diffusible factors. Curr Opin Neurobiol 9:355-363.

Steward O, Wallace CS, Lyford GL, Worley PF (1998) Synaptic activa- tion causes the mRNA for the IEG Arc to localize selectively near activated postsynaptic sites on dendrites. Neuron 21:741-751.

Wisden W, Errington ML, Williams S, Dunnett SB, Waters C, Hitchcock D, Evan G, Bliss TV, Hunt SP (1990) Differential expression of immediate early genes in the hippocampus and spinal cord. Neuron 4:603-614.

Wu GY, Deisseroth K, Tsien RW (2001) Spaced stimuli stabilize MAPK pathway activation and its effects on dendritic morphology. Nat Neurosci 4:151-158.

Xing J, Kornhauser JM, Xia Z, Thiele EA, Greenberg ME (1998) Nerve growth factor activates extracellular signal-regulated kinase and p38 mitogen-activated protein kinase pathways to stimulate CREB serine 133 phosphorylation. Mol Cell Biol 18:1946-1955.

Xu B, Gottschalk W, Chow A, Wilson RI, Schnell E, Zang K, Wang D, Nicoll RA, Lu B, Reichardt LF (2000) The role of brain-derived neurotrophic factor receptors in the mature hippocampus: modulation of long-term potentiation through a presynaptic mechanism involving TrkB. J Neurosci 20:6888-6897.

York RD, Yao H, Dillon T, Ellig CL, Eckert SP, Mccleskey EW, Stork PJ (1998) Rap1 mediates sustained MAP kinase activation induced by nerve growth factor. Nature 392:622-626. 